\title{
ADULT EDUCATION AND THE QUALITY OF LIFE
}

\author{
ALBERT TUIJNMAN
}

\begin{abstract}
The purpose of this study is to investigate the complementary role of adult education in influencing people's objective and subjective quality of life. The analytical strategy used to achieve this end is to estimate parameters in a path model which includes both objective indicators such as occupational status and earned income, and subjective indicators such as job satisfaction and perceived personal wellbeing. The investigation builds on Swedish data and employs the LISREL method in the fitting of the model to the data. The results indicate that adult education positively influences objective indicators of the quality of life. Even though adult education is found to relate to measures of perceived personal wellbeing, the hypothesis that it also influences the way men assess their life situation and evaluate their subjective quality of life cannot be confirmed.
\end{abstract}

Zusammenfassung - Zweck dieser Studie ist es, die ergänzende Rolle der Erwachsenenbildung in der Beeinflussung der objektiven und subjektiven Lebensqualität des Menschen zu erforschen. Die analytische Strategie, die zur Erreichung dieses Ziels angewandt wird, besteht darin, Parameter für ein Wegmodell zu finden, das sowohl objektive Indikatoren wie beruflicher Status und Gehalt beinhaltet, als auch subjektive Indikatoren wie Zufriedenheit im Beruf und empfundenes persönliches Wohlbefinden. Die Untersuchung beruht auf schwedischen Daten und wendet die LISREL-Methode an, um das Modell mit diesen Daten in Einklang zu bringen. Die Ergebnisse zeigen, da $\beta$ Erwachsenenbildung die objektiven Indikatoren der Lebensqualität positiv beeinflußt. Obwohl man herausfand, daß Erwachsenenbildung zum $\mathrm{Ma}$ des empfundenen persönlichen Wohlbefindens in Beziehung steht, läßt sich nicht die Hypothese bestätigen, daß sie auch darauf Einflu $\beta$ nimmt, wie die Menschen ihre eigene Lebenssituation einschätzen und ihre subjektive Lebensqualität beurteilen.

Résumé - L'objectif de la présente étude est d'examiner le rôle complémentaire de l'éducation des adultes dans l'action qu'elle exerce sur la qualité de vie objective et subjective des populations. La méthode d'analyse employée à cette fin consiste à évaluer les paramètres d'un modèle expérimental qui inclut aussi bien des indicateurs objectifs, tels que la situation professionnelle et le salaire, que des indicateurs subjectifs, tels que la satisfaction professionnelle et le sentiment de bien-être perçu par les individus. Cette recherche s'appuie sur des données suédoises et utilise la méthode LISREL pour adapter ce modèle aux données recueillies. Les résultats obtenus indiquent que l'éducation des adultes influe de façon positive sur les indicateurs objectifs de la qualité de la vie. Bien que l'on juge que l'éducation des adultes $a$ un rapport avec les mesures relatives au bienêtre perçu par les personnes, on ne peut vérifier l'hypothèse selon laquelle elle influence également la manière dont les gens évaluent leurs conditions de vie et leur qualité de vie subjective. 
It is generally believed that many people participate in programmes of adult education, not just for the sake of career advancement, but also to develop leisure interests, to enhance their sense of wellbeing and to increase their satisfaction with life in general. It would therefore be of interest to find out whether adult education influences people's perceptions of their quality of life. The review of previous studies presented below shows that this question has not yet received the research attention it deserves.

The study of the relationship between adult education and the quality of life is important because the purpose of adult education is not confined to conferring knowledge and skills for career mobility. For example, adult education seeks to promote social, cultural and political participation as an end in itself and as a means for improving the welfare of people. It aims to increase the general ability and willingness of people, in their role as citizens, to become involved in and to influence the further development of society. Participation in adult education is also regarded as constituting a means for personal enrichment, self-fulfilment and the development of leisure activities. Hence, because participation may well be motivated by subjective factors pertaining to people's perceptions of their nonmaterial conditions of living, the exclusive use of conventional economic criteria in assessments of the outcomes of adult education can be considered both incomplete and inadequate. Not only the equity aspect of participation in general programmes of adult education is important in this respect. The relationship between adult education and measures of perceived wellbeing should also be given attention in evaluation research.

\section{Purpose}

The purpose of this study is to investigate the role of adult education in complementing the effects of early formal education on the life chances and perceived wellbeing of a cohort of Swedish men born around the year 1928. The analytical strategy used to achieve this end is to develop a path model in which the influences of both early formal education and adult education on life chances and wellbeing can be assessed. In estimating this model the study seeks to answer the question whether those who take part in programmes of adult education score, on average, higher on measures of perceived wellbeing than those who do not participate in such programmes. In other words, do participants in adult education tend to see their lives as "fuller", "richer", and more "hopeful", worthwhile" and "interesting" than the general population? 


\section{Limitations and Advantages}

This study is based on the male segment only of the data collected in the "Malmö Study". Hence the most serious limitation of this study is its failure to include models which are related to the wellbeing of women. Because the population initially surveyed in the Malmö Study comprises all students who, in 1938, attended the third grade of both public and private schools in Malmö, the relevance of the data set should also be considered. Malmö city is located in the midst of a densely populated and industrialized region on the southern coast of Sweden. Even though most Swedes reside in towns and cities, the urban character of the population studied should be noted. Another issue of some concern in this paper is that a homogeneous age cohort is studied, so that the respondents were 56 years of age at the time the indicators of wellbeing employed in the analysis of data were measured.

Among the advantages of the study can be mentioned that the data are free from the effects of selection bias that would have arisen if the enrolment status of participants had been used as a sampling criterion. Second, it should be noted that the Swedish system of adult education is well developed by international standards and, hence, that a study estimating the relationships among youth education, adult education and general wellbeing involving data gathered in Sweden could therefore be of interest even to an international audience. Third, because the direction of an effect relationship is clearer if the variables involved in an analysis of data are ordered with respect to a time sequence, the data collected in the longitudinal Malmö Study can be put to excellent use in examining hypothesised relationships through their testing in a causal model.

\section{Theory and Previous Research}

Quality of life indicators are used to register the affective and cognitive reactions of men and women to economic and social processes. They usually involve self-assessments of personal wellbeing with respect to both life as a whole and specific life domains (Andrews and McKennell 1980). It is common to distinguish between objective and subjective indicators of the quality of life. An objective indicator would, for example, be a measure of income. In this case, its subjective counterpart would be a measure of personal satisfaction with income (Diener 1984; Alwin 1987).

Early formal education has been used as an antecedent variable of perceived wellbeing in many studies. These studies generally assume that individuals are influenced by educational practices not just in a passive 
manner as recipients, but as active and cognitively motivated participants. The influence of educational experiences on preferences, expectations, feelings, and emotional states is interpreted as a multiple force which contributes not only towards the shaping of personality characteristics, but also to social psychological traits such as self-esteem and perceived personal wellbeing. In this view, education, income, health, employment, perceptions of work and leisure, age and self-esteem are seen as factors which facilitate or limit opportunities for participation and social interaction. Poor health and an initially low level of formal education, for example, have been found to reduce psychological wellbeing (Thoits 1983). As a consequence, since educational attainment is believed to influence life chances and the shaping of perceptions of self and society, it is possible that educational experiences, including those gained through voluntary participation in adult education, also influence the way people assess their own global life situation and evaluate their personal wellbeing.

However, studies involving representative samples of adult populations have generally found statistically insignificant or weak relationships between formal educational attainment and perceived wellbeing (Campbell et al. 1976; Moum 1983; Mutran and Reitzes 1984; Inglehart and Rabier 1986). After reviewing studies regarding quality of life, Abbey and Andrews (1986) conclude that demographic and social background variables, such as age, sex, education, income, marital status, and stage in the family life cycle show only weak relationships, if any, to most selfassessments of life quality. Even when several of these factors are used together in a multivariate analysis, they usually explain less than 15 per cent of the variation in perceived wellbeing as a whole, and rarely more than that in assessments of specific life domains. Another general finding is that the relationship between early formal education and perceived wellbeing is negative for some groups. For example, Alwin (1987) found that, after due allowance had been made for differences in income levels, people with more education were less satisfied with their global life situation. Several theories provide explanations for this finding (for a discussion see Rosenberg 1981; Gooderham 1987). In the social psychological perspective, reference group theory is perhaps the most dominant approach. This theory can be viewed as arguing that negative correlations between education, life satisfaction and perceived wellbeing arise because the relatively better educated groups tend to have higher aspirations, expectations and demands and, as a result, employ other reference standards in assessing their subjective life situation.

No studies have been found from previous research which have directly investigated the relationship between adult education and perceived wellbeing. Hence, no direct guidance was available for determining the 
specification of a causal model. However, positive correlations between psychological wellbeing, social interaction and positive perceptions of major events in life are reported (McLanahan and Sörensen 1984; Michalos 1986). Because people usually take part in programmes of adult education on a voluntary basis and, moreover, since participation in adult education generally involves social interaction, these findings could perhaps be interpreted as supporting the hypothesis that participation in adult education positively influences life satisfaction and aspects of perceived wellbeing.

\section{Validity and Reliability Issues}

The development of social indicators has been given some priority by both policy makers and research workers, especially since the mid-1960s. The optimism which characterized the development of the social sciences as policy-oriented fields of research was reflected in much of the early work on wellbeing and quality of life. However, at least initially researchers were more concerned with problems of validity and the reliability of the variables used in obtaining information for the calculation of social indices than with questions of theory and interpretation. The issue of whether the quantification of quality of life in a population was at all meaningful elicited less interest than the technical problems which were encountered in the construction of indicators. As a result, even though general methods have now become available, less headway has been made with respect to the philosophical and theoretical underpinnings of research into the quality of life (Griffin 1986).

A distinction is commonly made between measures tapping people's "satisfaction" or "happiness" with respect to specific domains of life experience on the one hand, and global reports of the nature and quality of life experiences on the other. For example, Campbell et al. (1976) used life descriptions, reports of happiness, and measures of a sense of satisfaction with life to study the quality of life among a representative sample of the adult population in the United States. The instruments used included ten semantic differential scales of seven categories each which asked respondents how they could characterize their lives at present. Eight of these scales were combined into a composite "Index of General Affect". Since the publication of The Quality of American Life (Campbell et al. 1976), this index has found extensive application in other investigations.

Three major criticisms have been levelled against much quality of life research. The first concerns the atheoretical orientation of many studies. The second criticism deals with the influence of expectations, aspirations 
and other reference frames on life characterizations and self-reports of the perceived quality of life. It is well known from previous research that standards of reference are important for an understanding of the findings (Inglehart and Rabier 1986). Whether or not a study should aim to control for differences in levels of aspiration depends on the kinds of issue the study seeks to address. Since the purpose of this paper is to find out whether particular relationships exist rather than to explain how such relationships might have come about, the influence of frames of reference on reports of wellbeing are not explicitly taken into account in the analyses of data that follow.

The third criticism, which is mainly methodological, focuses on the reliabilities of the measures used to assess dimensions of wellbeing. While many different indicators of perceived wellbeing have been developed since the 1960s, their proneness to measurement error and response bias is noted by most workers in this field. Previous studies have shown that self-reported health variables, life characterizations and measures of wellbeing are beset by systematic errors of measurement (Moum 1983; Butler et al. 1987). A common source of error is associated with the influence of response styles, such as the effect of response acquiescence and trait desirability on self-ratings. Different methods are available to minimize the effects of such instances of response error. For example, one possibility would be to carry response style variables, which tap inconsistent or self-contradictory answers to related questions, through all stages of the analysis. However, a previous study employing data derived from the Malmö Study (Tuijnman 1989) found that response error is not a major problem in the data set examined.

\section{Data and Measurement of Variables}

The Malmö Study comprises data gathered in Sweden from 1937 to 1988 for a cohort of 1542 men and women who, at the age of ten years, attended the 61 third-grade classes in all public and private schools in Malmö. The study was initiated in 1937 with the aim of investigating the relationship between home background and tested cognitive ability. The cohort has been followed up since then and data have regularly been added to the study. The most recent data collection took place in 1984 . On this occasion, a questionnaire was administered in order to gather information about, among other variables, occupational careers, participation in adult education, attitudes to work and perceived wellbeing. The manifest variables used in this paper have been described in earlier publications emanating from the Malmö Study (Husén 1969; Fägerlind 
1975; Tuijnman 1989). Hence, the measures of adult education and wellbeing excepted, there is no compelling need to repeat these definitions here.

Two indicators of adult education are used. The first is a dichotomous measure indicating whether or not a respondent took part in an adult education activity between 44 and 56 years of age. The second indicator is measured as follows. At 35, 43 and 56 years of age, the people surveyed in the Malmö Study were asked to name any adult educational activities in which they had taken part during successive time intervals: (1) from age 30 to 35 , (2) from age 36 to 43 , and (3) from 44 to 56 years of age. The group was also asked about the subjects or subject areas they had studied. This information was used to assess the accumulation of adult learning experiences over a twenty-five year time span, from 30 to 56 years of age, by calculating weighted linear combinations of individual scores on the three variables describing participation in programmes of adult education during each of the three time periods mentioned above.

The measures of perceived wellbeing employed in this study are based on responses to nine semantic differential scales. In the 1984 questionnaire, the men surveyed in the Malmö Study were asked to check a point on these bipolar rating scales which best described their view of life at present. The specific adjective pairs used in the questionnaire are indicated in Table 1. Whereas each item was originally measured on a sevenpoint scale, those used in this report have only five categories. Although the raw scores on these five-category scales are less skewed, entirely normal distributions are not achieved in spite of the restriction of range. Mean scores, standard deviations and factor loadings of the rescaled measures used in the analysis of data are presented in Tuijnman (1989).

\section{Results}

\section{Mean Score Comparisons}

Table 1 presents the results of an analysis of data which seeks to compare the men who participated in adult education with those who did not, with respect to their mean scores on measures of job satisfaction, prospects for career development and perceived general wellbeing. Effect size indices are used to denote the size of the standardized difference between the two comparison groups, participants and nonparticipants. Effect size indices with values exceeding the 0.20 threshold level are considered to be significant (Hedges and Olkin 1985). However, since causal inferences cannot be made from effect sizes, the indices can only be interpreted as 
Table 1. Comparing participants in adult education with nonparticipants with regard to mean scores on selected variables $(\mathrm{N}=671)$.

\begin{tabular}{|c|c|c|c|}
\hline Variable description & \multirow{2}{*}{$\begin{array}{l}\text { Nonparticipants } \\
\overline{\mathrm{x}}\end{array}$} & \multirow{2}{*}{$\begin{array}{l}\text { Participants } \\
\overline{\mathbf{x}} \\
3.74\end{array}$} & \multirow{2}{*}{$\begin{array}{l}\begin{array}{l}\text { Effect } \\
\text { sizes } \\
\delta\end{array} \\
\mathbf{0 . 3 3}\end{array}$} \\
\hline 1 Prospects for future employment & & & \\
\hline 2 Risk of becoming unemployed & 3.54 & 3.22 & -0.32 \\
\hline 3 Perceived overall success in Life & 2.63 & 2.87 & 0.28 \\
\hline 4 Feelings about the present job & 3.23 & 3.43 & 0.29 \\
\hline $\begin{array}{l}5 \text { I would recommend own job to } \\
\text { friend }\end{array}$ & 3 & & 0.22 \\
\hline 6 I would take the same job again & 3.84 & 4.05 & 0.18 \\
\hline 7 I would rather look for a new job & 3.96 & 4.17 & 0.16 \\
\hline 8 Life is boring ... interesting & 3.53 & 3.93 & 0.31 \\
\hline 9 Life is empty ... full & 3.63 & 3.89 & 0.21 \\
\hline 10 Life is disappointing... & & & \\
\hline rewarding & 3.65 & 3.92 & 0.21 \\
\hline 11 Life is useless ... worthwhile & 3.71 & 3.97 & 0.20 \\
\hline 12 Life is monotonous ... fascinating & 3.55 & 3.81 & 0.20 \\
\hline 13 Life is miserable ... enjoyable & 3.90 & 3.98 & 0.07 \\
\hline 14 Life is discouraging . . . hopeful & 3.59 & 3.71 & 0.09 \\
\hline 15 Life is hard ... easy & 3.16 & 3.00 & -0.11 \\
\hline 16 Life is tied-down ... free & 3.70 & 3.68 & -0.01 \\
\hline
\end{tabular}

Note: Indices set in bold face are meaningful, with values greater than the 0.20 level used as the threshold for significance.

suggesting whether or not the associations between measures of participation in adult education and the criterion variables are meaningful.

The entries recorded in Table 1 demonstrate that those who took part in programmes of adult education during the period from 44 to 56 years of age scored generally higher on 14 measures of job satisfaction, prospects for career development and wellbeing assessed at age 56. The differences between the comparison groups are generally meaningful since most effect sizes exceed the 0.20 threshold level. The message conveyed by the data is that, relative to those who were not reached by the adult education system, those who took part tend to regard themselves as running less risk of becoming unemployed, have more favourable prospects for future employment and tend to take a more positive view of their own achievements. Noteworthy results are also obtained in comparing the groups with respect to their mean scores on nine semantic differential scales tapping various dimensions of the respondents' charac- 
terization of life. The largest difference $(0.31)$ is estimated for the scale describing in qualitative detail whether the respondents view their lives as interesting or boring. The effect sizes indicate that the participant group tends to lean toward descriptions characterizing life as "full", "rewarding", "worthwhile" and "fascinating", more than is normal in the population as a whole. The effect sizes also demonstrate that two scales deviate from the general pattern found in the data, namely, "hard" vs. "easy" and "tieddown" vs. "free". Even though the differences between the mean scores are not significant in these cases, the negative signs associated with the effect sizes suggest that those who do not take part in programmes of adult education and training tend, in the main, to consider life to be both easier and freer than do those in the participant group. It should also be noticed that the differences between the two comparison groups on the scales "miserable" vs. "enjoyable" and "discouraging" vs. "hopeful" are too small to be of practical interest.

\section{Index of General Wellbeing}

The association between adult education and general wellbeing is further examined in this section. It is useful to adopt the same analytical strategy as the one used by Campbell et al. (1976) in their survey of the quality of life in the United States. They developed a composite index of wellbeing in order to investigate whether there were any systematic dissimilarities in the way the groups involved in the different categories associated with the antecedent variables characterized their life situation and assessed their sense of wellbeing.

The first step taken in the building of a composite index is to estimate the variances, factor loadings and weights of the measures of general wellbeing by using the maximum likelihood factor analytic procedure. An exploratory factor analysis indicated problems associated with two of the nine semantic differential scales. The deviant factor patterns found in the cases of the two scales "life is hard" vs. "easy" and "tied-down" vs. "free" are consistent with the results obtained by Campbell et al. (1976), who relegated these divergent items from their "Index of General Affect". For the same reasons (see also Table 1) both scales are excluded from further analysis in this study. These two items excepted, the scales describing the respondents' views of life loaded to a moderate degree on mostly one construct. As the seven remaining scales can be considered to describe aspects of perceived life affect or the general quality of life, it would seem defensible to employ the generic label "general wellbeing" to denote the common factor. In order to enhance the robustness of the index, unweighted scoring procedures are used in the second step to calculate raw 
score values. These are then transformed to standard scores with a zero mean and standard deviation of one unit. It should be noted that the resulting distribution of standard scores is negatively skewed.

The results of a comparison of within-group mean differences on the index of wellbeing for groups differing in the frequency and level of participation in adult education are presented in Fig. 1. The curve shows mean standard scores on the index of wellbeing estimated for five categories denoting cumulative participation in all forms of adult education assessed over the period from 30 to 56 years of age. As can be expected on the basis of the effect size indices included in Table 1, the data indicate that adult education is positively related to the sense of wellbeing reported by the men surveyed, since a gradual increase is found in the mean standard scores of successive groups. However, it should also be noted that some doubt is cast on the strength and the significance of the associations, since the values lie close to the mean.

\section{Mutivariate Data Analysis}

In order to facilitate a further exploration of the links between youth

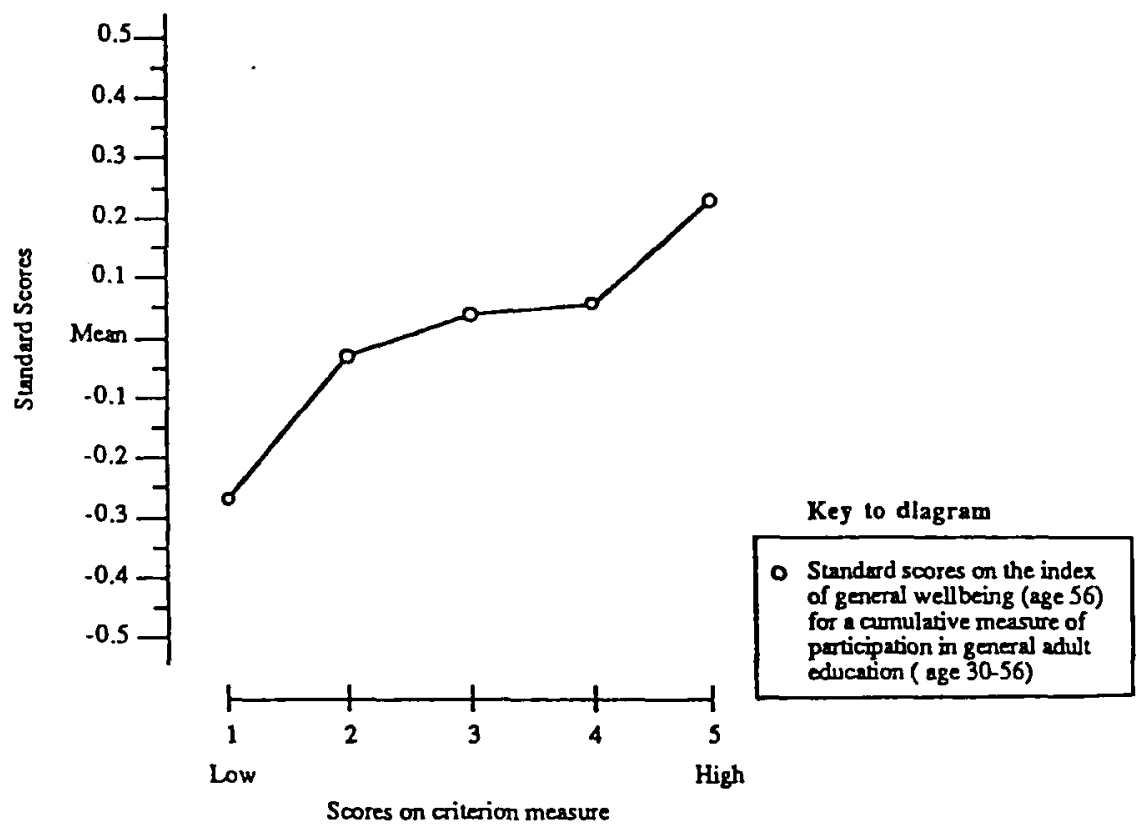

Fig. 1. Standard scores on the index of wellbeing at age 56 for different levels of participation in adult education. 
education, adult education and wellbeing, a multivariate analysis of data is undertaken. Figure 2 presents a diagram of a hypothesised path model comprising eight theoretical variables. The model is estimated in the attempt to answer the following questions. First, how does youth educational attainment relate to general wellbeing measured late in the adult life cycle? Second, is there a positive relationship between participation in adult education and perceived general wellbeing? Third, to what extent are other, intervening variables such as prospects for future employment and job satisfaction involved in these relationships? The starting point for the development of the path model is the argument that adult education aims not only to improve the objective living conditions of participants assessed by using measures of occupational status and earned income, but also to enhance their subjectively perceived quality of life. The diagram in Fig. 2 indicates the network of relationships which is hypothesised.

Table 2 presents standardized path coefficients estimated in the model of general wellbeing. These estimates are obtained in a structural equation model in which the effects of missing data, measurement errors and significant error co-variances are minimized. The model is estimated in three main stages, using the maximum likelihood approach and the

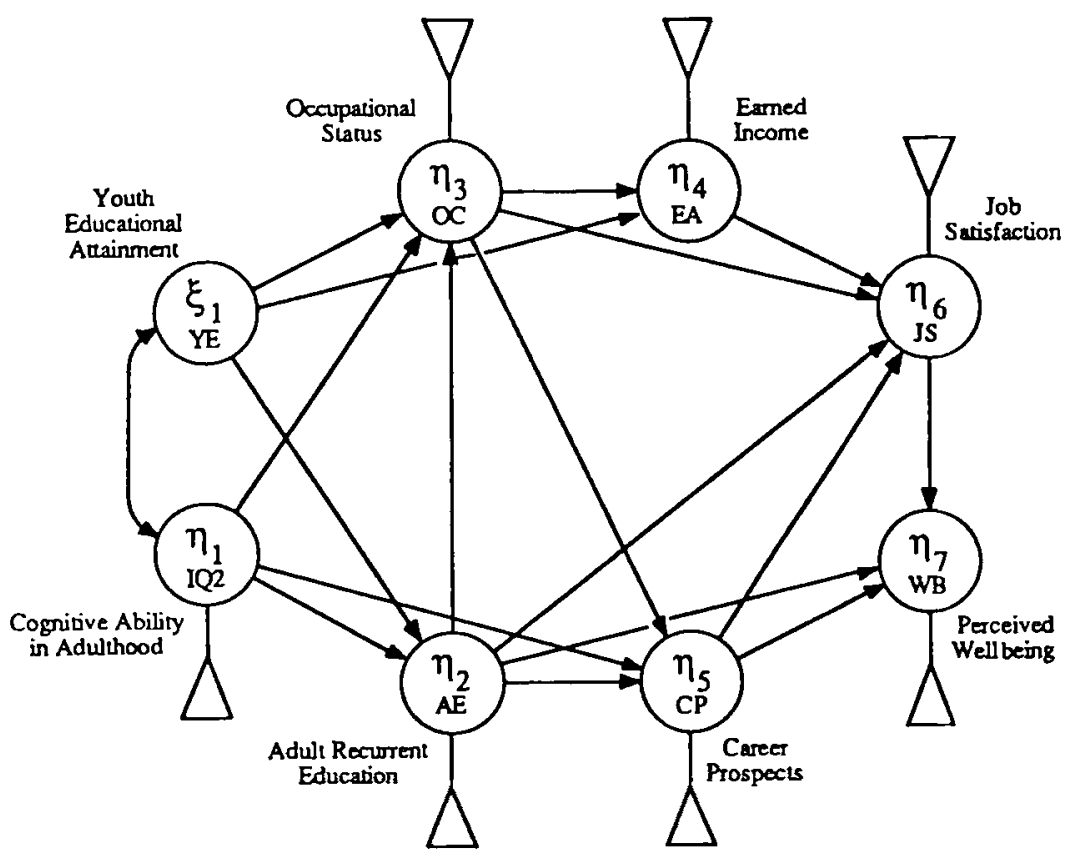

Fig. 2. Path diagram for a hypothesised model linking adult education and wellbeing. 
method of linear structural relations analysis (Jöreskog and Sörbom 1989). A fully recursive and just-identified model is estimated at first. The model is modified in the second stage by relaxing those error constraints which, if set free, would significantly improve the 'goodness of fit' of the data to the model. The over-identified model is estimated in the third stage. Here, standard error estimates are used to examine whether the probability of obtaining a certain path coefficient is significantly different from zero. The approach subsequently taken is to delete all trivial paths from the structural model. Table 2 presents the solution obtained in estimating the final model. It should be emphasised that its "goodness of fit" is adequate ( $\chi^{2}$ is 129.9 with 118 degrees of freedom). Unstandardized estimates of all parameters in the model, as well as their levels of statistical significance, are given in Tuijnman (1989: 214, 253-254). It follows from the above that the standardized path coefficients included in Table 2 are statistically significant at least at the five per cent level.

It can be seen from Table 2 that adult education influences occupational status at age 56. While the direct effect of adult education on earned income is not significantly different from zero, its influence mediated by occupational status is of enough substance $(0.39 \times 0.59=0.23$, s.e.

Table 2. Significant path coefficients in a regression model of adult education and perceived general wellbeing.

$\begin{array}{llllllll}1 & 2 & 3 & 4 & 5 & 6 & 7 & \mathrm{R}^{2}\end{array}$

1 Level of Formal Youth Education, age 20

2 Index of Intelligence Test Scores, age 20

n.a.

3 Index of Recurrent Adult Education. age $30-56$

0.24

0.28

0.23

4 Occupational Status at age 56

0.37

0.08

0.150 .39

$\begin{array}{lll}0 & 0 & 0.59\end{array}$

0.56

5 Earned Income at age 56

$\begin{array}{lll}0 & -0.180 & 0.360\end{array}$

0.09 age 56

0 age 56

$\begin{array}{lllll}0 & 0 & 0.09 & 0 & 0.50\end{array}$

0.28

8 Index of Perceived General Wellbeing at age 56

$\begin{array}{llllllll}0 & 0 & 0.08 & 0 & 0 & 0.34 & 0.22 & 0.27\end{array}$

Notes: $\mathrm{N}=671$.

Maximum likelihood, standardized solution.

All coefficients are significant with t-values greater than two. The standard errors of estimates are reported in Tuijnman (1989: 253-254).

The full structural indicator model is graphically shown in Tuijnman (1989: 214). 
0.03 ) to justify the conclusion that adult education and workplace training must be considered to contribute to the quality of life of participants as assessed by using objective indicators. Hence, the hypothesis advanced mainly by research workers in the economics of recurrent education, that investment in further education and training of relevance to an individual's occupational qualifications produces both social and economic benefits, is supported by the analysis of data.

Moreover, the results indicate that cognitive ability and occupational status at age 56 directly influence people's self-evaluation of their prospects for career development $(-0.18$ and 0.36$)$. While the direct effect of adult education on career prospects is not significant at the five per cent level its indirect effect mediated by occupational status $(0.39 \times 0.36=$ 0.14 ) exceeds the 0.10 level and, hence, can be considered meaningful. This indicates that the effect, if any, of adult education on prospects for career development depends upon the level of the job an employee occupies in the labour market. The negative influence of cognitive ability in adulthood on career prospects is difficult to explain. As cognitive ability has a positive effect $(0.10)$ on career prospects mediated by adult education and occupational status, the negative direct effect in question can have arisen because the intellectually gifted men who did not reach a relatively high occupational position tend to view their own career prospects as more unfavourable than the less gifted groups. Again, this interpretation emphasises the crucial role of previous occupational attainments.

The data included in Table 2 show that neither adult education nor earned income exerts direct influence on job satisfaction. In the case of the latter relationship this finding is consistent with much previous research (Abbey and Andrews 1986). The result with regard to adult education could reflect the fact that recruitment to programmes of adult education and particularly to workplace training does not necessarily occur on an entirely voluntary basis. Two variables, occupational status and prospects for career development, influence job satisfaction at 56 years of age. The path from career prospects is strong $(0.50)$ while that from occupational status is weak (0.09). This suggests that factors such as job insecurity and unfavourable prospects for future employment have important negative consequences for job satisfaction. Likewise, good career prospects are associated with positive job satisfaction. Since adult education influences occupational status, and since the latter variable influences career prospects, it can be postulated that adult education has an effect on job satisfaction mediated by occupational status and prospects for career development. This hypothesis is tentatively confirmed because the indirect effect of adult education on job satisfaction can be shown to be weak but 
meaningful $(0.10$, s.e. 0.02$)$. It follows from the above that the weak correlation between adult education and job satisfaction depends, first, on the status associated with the occupation and, second, on whether the job provides some opportunity for future career development. Hence, it seems that a policy of enhancing job satisfaction by providing workers with opportunities to take part in programmes of adult education is likely to fail, unless the activity leads to a new job with higher prestige or to prospects of acquiring a more desirable job in the future.

The model accounts for 27 per cent of the variance in general wellbeing, indicated by variables measuring the worthwhileness and fullness of life. Significant direct effects on wellbeing are exerted by three variables. The effect of career prospects $(0.34)$ is greater than that of job satisfaction $(0.22)$, while the influence of adult education $(0.08)$ is weak. A problem of interpretation exists because the size of the path coefficient found for the effect of adult education on perceived wellbeing is small, although its statistical significance is not in doubt (s.e. 0.03). The significant, albeit weak, effect of adult education on general wellbeing supports the proposition that the purpose of adult education is not restricted to one of conferring knowledge and skills for career mobility.

\section{Conclusion}

That adult education and subjectively perceived wellbeing are positively related is established beyond reasonable doubt in an analysis of data that sought to compare the mean scores on measures of wellbeing of participants in adult education with those who were not reached by the system. The participant groups tend consistently to lean toward descriptions characterizing life as being "full", "interesting", "rewarding", "worthwhile" and "fascinating", to a greater extent than the total population. That the association between adult education and general wellbeing is found to be significant is an important finding, not least because many other factors can be expected to co-vary with this dependent variable. However, the hypothesis that adult education has a significant effect on the way people assess their own life situation and evaluate their subjective wellbeing cannot be confirmed, since the magnitude of the path coefficient obtained in the regression analysis is - although statistically significant - too small to be of interest from a substantive point of view. However, since the results also indicate that adult education constitutes a factor of importance in explaining differences in occupational attainment between workers with similar instrumental qualifications, the study supports the conclusion that adult education contributes to objective quality of life. 
The data set available for analysis in this paper is in many ways unique and permits the examination of questions that have not previously been addressed. As some of the results obtained in this investigation are new and not supported by previous research, they should be interpreted cautiously. Further research drawing upon other populations is clearly needed to establish the role of adult education in influencing people's sense of general wellbeing. In view of the nature of the questions addressed, it would seem that initially qualitative data collected by means of interviews would be most useful for future research into the relationship between adult education and subjectively perceived quality of life. Subsequently, appropriate scales need to be developed. Besides the validation of the findings of this study, future studies should evidently attempt to examine data which involve and are relevant to the quality of life of women.

\section{References}

Abbey, A. and Andrews, F. M. 1986. Modeling the Psychological Determinants of Life Quality. In: F. M. Andrews, ed., op. cit. (85-116).

Alwin, D. F. 1987. Distributive Justice and Satisfaction with Material Well-being. American Sociological Review 52: 83-95.

Andrews, F. M., ed. 1986. Research on the Quality of Life. Ann Arbor. MI: Institute for Social Research, The University of Michigan.

Andrews, F. M. and McKennell, A. C, 1980. Measures of Self-reported Wellbeing: Their Affective, Cognitive, and other Components. Social Indicators Research 8: 127-155.

Butler, J. S., Burkhauser, R. V., Mitchell, J. M. and Pincus, T. P. 1987. Measurement Error in Self-reported Health Variables. Review of Economics and Statistics 69: $644-650$.

Campbell, A., Converse, P. E. and Rodgers, W. L. 1976. The Quality of American Life: Perceptions, Evaluations, and Satisfactions. New York: Sage.

Diener, E. 1984. Subjective Well-being. Psychological Bulletin 95: 542-575.

Fägerlind, 1. 1975. Formal Education and Adult Earnings. Stockholm: Almqvist and Wiksell.

Gooderham, P. N. 1987. Reference Group Theory and Adult Education. Adult Education Quarterly 37: 140-151.

Griffin, J. 1986. Well-being. Its Meaning, Measurement, and Moral Importance. Oxford: Clarendon Press.

Hedges, L. V. and Olkin, I. 1985. Statistical Methods for Meta-analysis. London: Academic Press. 
Husén, T. 1969. Talent, Opportunity and Career. Stockholm: Almqvist and Wiksell.

Inglehart, R. and Rabier, J. R. 1986. Aspirations Adapt to Situations. But why are the Belgians so much Happier than the French? A Cross-cultural Analysis of the Subjective Quality of Life. In: F. M. Andrews, ed., op. cit. (1-56).

Jöreskog, K. G. and Sörbom, D. 1989. LISREL 7. A guide to the program and applications. Chicago: SPSS Publications.

McLanahan, S. S. and Sörensen, A. B. 1984. Life events and Psychological Wellbeing. Social Sciences Research 13: 111-128.

Michalos, A. C. 1986. Job Satisfaction, Marital Satisfaction and the Quality of Life: A Review and a Preview. In: F. M. Andrews, ed., op. cit. (57-83).

Moum, T. 1983. The Role of Values and Life Goals in Quality of Life: On Measuring and Predicting Subjective Well-being. In: Socio-economic Studies 5 , (111-177). Paris: Unesco.

Mutran, E. and Reitzes, D. C. 1984. Intergenerational Support Activities and Well-being among the Elderly. American Sociological Review 49: 117-130.

Rosenberg, M. 1981. The Self-concept: Social Product and Social Force. In: M. Rosenberg et al., eds., Social Psychology, (593-624). New York: Basic Books.

Thoits, P. A. 1983. Multiple Identities and Psychological Wellbeing: A Reformulation and Test of the Social Isolation Hypothesis. American Sociological Review 48: $174-187$.

Tuijnman, A. 1989. Recurrent Education, Earnings, and Well-being: A Fifty-Year Longitudinal Study of a Cohort of Swedish Men. Stockholm: Almqvist and Wiksell. 